\title{
"FORMATION OF THE MODEL IMAGE OF A MODERN TEACHER IN THE SYSTEM OF PROFESSIONAL DEVELOPMENT"
}

\author{
Firuza Narzikulova \\ Doctor of Philosophy in Psychological Sciences (PhD),Associate Professor of the Department of"Pedagogy, Psychology and \\ Educational Technologies" of the Samarkand Regional Center forAdvanced Training and Retrainingof Public Education Workers, \\ Uzbekistan. E-mail:firuza-narzikulova@mail.ru
}

\begin{abstract}
:
The article presents a model for the implementation of the system for the development of the teacher's professional image, which is a system consisting of separate, interconnected elements, which ensures the integrity of the process of developing the teacher's professional image. In the article, an important point of approbation of the model proposed by the author, the introduction of hypothetically predictable pedagogical conditions is presented. The article presents a specially organized empirical study in order to clarify the relevance of the theoretical conclusions.
\end{abstract}

Keywords:

Professional image of a teacher, professional model, professional conditions, professional education, professional system, development of a pedagogical image, empirical research and etc.

Article Received: 18 October 2020, Revised: 3 November 2020, Accepted: 24 December 2020

\section{INTRODUCTION}

Recently, socio-psychological sciences have been constantly paying attention to the issues of selfeducation, self-improvement and selfdetermination of the individual, relying more and more on the desire of a person to create the strength of his profession, by building a life strategy and planning professional activities. Such a desire should be the main task of professional education, both for future teachers and in the process of improving the qualifications of teaching staff. Involving an individual to create an image in the imagination or in the context of our study of a model, a future profession, as a result of professional training, can become an incentive force and turn into a purposeful formation of a professional image model [6]. As practice shows in psychological research, a model, as a rule, is understood as a certain scheme, or an action plan aimed at realizing the corresponding goal. As practice shows in psychological research, a model, as a rule, is understood as a certain scheme, or an action plan aimed at realizing the corresponding goal.

\section{LITERATURE REVIEW}

In turn, modeling as a method for studying the relevant phenomena, as well as processes, is widely used in modern psychology, forming the basis of a psychological experiment. In this aspect, most scientists are of the opinion that modeling a psychological phenomenon, a process allows you to visually represent the nature of the structure of the studied, to predict in advance various possible transformations and the use of these factors in solving the tasks $[1 ; 3 ; 4 ; 5 ; 8]$. Many scientists, researchers, considering modeling as a whole, note that the model should reflect an imaginary or materially realized system capable of reproducing the object of research and replacing it in such a way that its study will provide an opportunity to obtain new information about the object [2;9]. Researchers identify the following main qualities of the model: conformity; purposefulness; neutrality to 
subjective assessments and preferences of the participants in the modeling; abstraction from some details and parameters of the original system.

\section{RESEARCH METHODS}

According to our position, modeling in our psychological research gives us the opportunity to formalize, schematize and significantly simplify and systematize the understanding of the phenomenon under study, which would allow us to assume about the relationships and conditions of improvement, to track those of its characteristics that play a determining role in research and are subject to further research. Thus, adhering to the above formulated approach to the process of modeling the structure of the teacher's professional image, we organized and conducted an expert assessment of generalized individual psychological characteristics characterizing the image. 135 specialists, both female and male, with significant experience in the field of education, took part as experts.

In order to standardize the results obtained, simplify organizational issues, the expert assessment was carried out according to a preprepared expert questionnaire, the basis of which is made up of 32 identified, based on the results of theoretical analysis, generalized individual psychological characteristics (structural components) that characterize the teacher's image. To differentiate the structural components, the questionnaire includes a fifteen-point assessment scale, where the range: from 1 point to 3 points - a low level of compliance with the assessed structural component (not significant); from 4 points to 6 points - below the average level of compliance with the assessed structural component (not significant); from 7 points to 9 points - the average level of compliance with the assessed structural component; from 10 points to 12 points - above the average level of compliance with the assessed structural component (highly significant); from 13 points to 15 points - a high level of compliance with the assessed structural component (highly significant).

\section{ANALYSIS OF THE EXPERIMENT}

Based on the results of the expert assessment, all the results obtained were summarized in a single table to calculate basic statistical data (average score, median, etc.) for each assessed structural component of the teacher's professional image. Thus, the analysis in the context of average statistical points shows that according to experts, out of 32 structural components, 12 (37.5\%) characterize the professional image of a modern teacher at a highly significant level, i.e. at high (15.6\%, 5 characteristics) and above average (21.9\%, 7 characteristics) levels (Fig. 1).

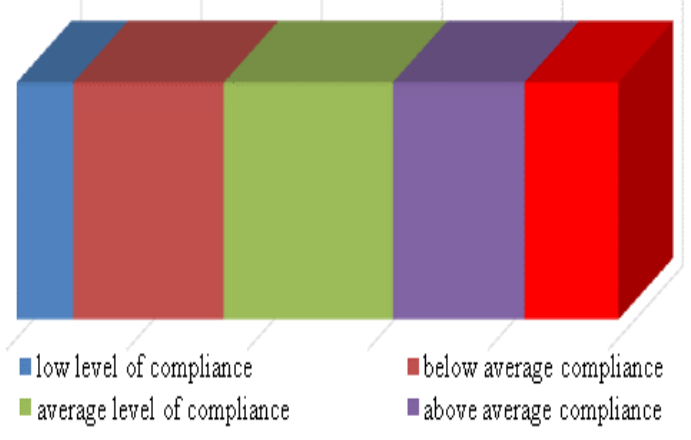

Figure: 1. the results of an expert assessment of the structural components of the professional image of a primary education teacher in the context of average points $(n=135)$

Accordingly, the remaining $20(62.5 \%)$ structural bleeds, according to experts, characterize the phenomenon under study at: low level $-9.4 \%$ / 3 characteristics; below the average level - 25\% / 8 characteristics; average level $28.1 \%$ / 9 characteristics.

Analyzing as a whole in the context of other basic statistical data, it is considered appropriate to note that when experts evaluated 20 (62.5\%) structural components that were classified as low, below average and average level of compliance, the minimum and maximum estimated scores on average varied from 3,15 to 9.4. At the same time, when assessing highly significant $(37.5 \%, 12$ characteristics) structural components, the minimum and maximum estimated scores varied on average from 9.08 to 14, 83. This fact also confirms the results of the above analyzes and allows you to select a list of 
relevant structural components of the professional image of a modern teacher (chart 1).

\begin{tabular}{|c|c|c|c|c|c|c|}
\hline № & $\begin{array}{c}\text { Names of the assessed } \\
\text { characteristics of the } \\
\text { primary education teacher }\end{array}$ & 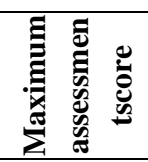 & 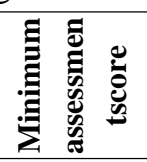 & 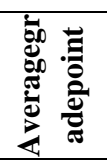 & 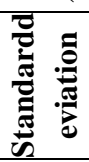 & 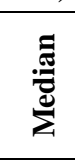 \\
\hline 1 & $\begin{array}{l}\text { the ability to regulate } \\
\text { one's behavior in } \\
\text { communicative situations }\end{array}$ & 15 & 12 & 14,09 & 0,89 & 14 \\
\hline 2 & $\begin{array}{l}\text { ability to adapt to social } \\
\text { conditions }\end{array}$ & 15 & 12 & 13,72 & 0,92 & 14 \\
\hline 3 & $\begin{array}{c}\text { the ability to } \\
\text { independently overcome } \\
\text { emerging life problems }\end{array}$ & 15 & 10 & 13,1 & 1,03 & 13 \\
\hline 4 & lowlevelofconflict & 15 & 8 & 12,94 & 1,27 & 13 \\
\hline 5 & $\begin{array}{c}\text { communicationandorgani } \\
\text { zationalskills }\end{array}$ & 15 & 9 & 12,78 & 1,44 & 13 \\
\hline 6 & emotionalintellect & 15 & 8 & 12,45 & 1,44 & 13 \\
\hline 7 & $\begin{array}{c}\text { the ability to self-regulate } \\
\text { emotional states that arise } \\
\text { in a communicative } \\
\text { situation } \\
\end{array}$ & 15 & 9 & 12,33 & $1, \mathbf{4 3}$ & 12 \\
\hline 8 & balancedemotionality & 15 & 8 & 12,24 & 1,95 & 12 \\
\hline 9 & empathicabilities & 15 & 8 & 12,22 & 1,5 & 12 \\
\hline 10 & developedreflexivity & 15 & 8 & 11,94 & 1,45 & 12 \\
\hline 11 & communicativetolerance & 14 & 9 & 11,41 & 1,15 & 11 \\
\hline 12 & $\begin{array}{l}\text { strivingforself- } \\
\text { development }\end{array}$ & 14 & 8 & 11,4 & 1,18 & 11 \\
\hline & Averagevalues & 14,83 & 9,08 & 12,19 & 1,42 & 12,11 \\
\hline
\end{tabular}

\section{Chart 1. Actual structural components of prof. the image of a modern teacher $(n=135)$}

In order to facilitate the perception of the selected list of relevant structural components of the phenomenon under study, they are classified according to the principle of the significance of expert assessments. So, the first component included the actual structural components that received the maximum indicators of the distribution center (median - 14 points), as well as the maximum average statistical value of expert points: the ability to regulate one's behavior in communicative situations - 14 points; the ability to adapt to the conditions of the social environment - 14 points. The second component of the professional image of a modern primary education teacher includes the following relevant structural components, which were evaluated by experts at 13 points (median): the ability to independently overcome emerging life problems -
13 points; low level of conflict - 13 points; communication and organizational skills - 13 points; emotional intelligence - 13 points. Accordingly, the third component covered the actual structural components, which were assessed by experts at 12 points (median): the ability to self-regulate emotional states that arise in a communicative situation - 12 points; balanced emotionality - 12 points; empathic abilities - 12 points; developed reflexivity - 12 points. The final fourth component of the phenomenon under study included the remaining actual structural components estimated at 11 points (median): communicative tolerance - 11 points; striving for self-development - 11 points (Fig. 2).

Thus, the analysis of the methodological approaches to the modeling process shows that, taking into account the goals and objectives of our 
research, it is advisable to understand the model of the structure of the professional image of a modern teacher as an integral set of interdependent structural elements, where each of them is considered taking into account the degree of influence on the studied phenomenon generally. In essence, the studied model is a hierarchically ordered system of interrelated, interdependent and conditionally distinguished content elements, which together reflect the nature of a holistic understanding of the image of a modern teacher. Such an approach makes it possible to reasonably approach the process of building an appropriate model, concretize the stages of its development, and also outline the optimal ways of effectively developing the image of a modern teacher.

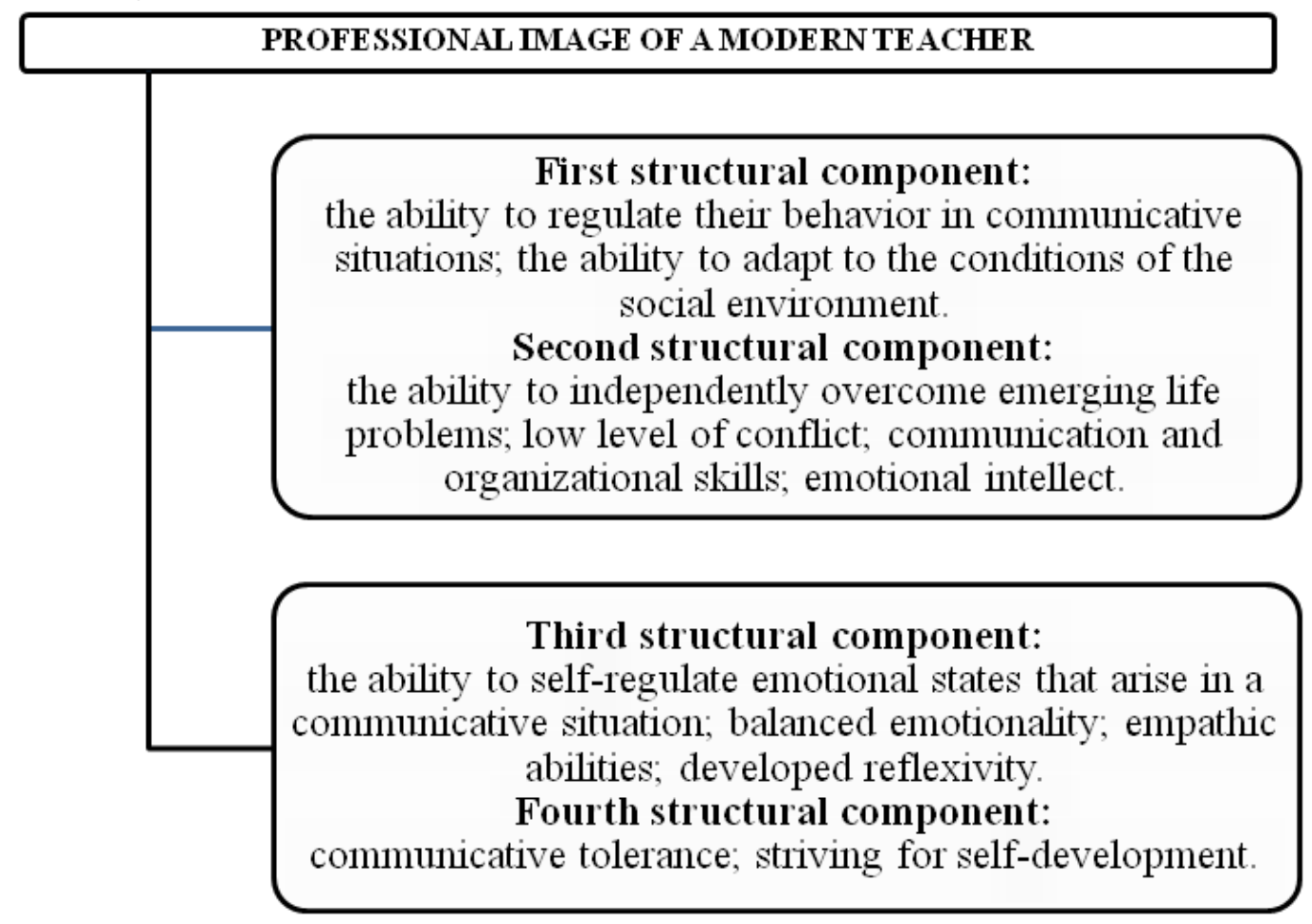

Figure: 2. Model of the structure of the professional image of a modern teacher

\section{CONCLUSION}

Thus, our expert assessment $(\mathrm{n}=135)$ of the theoretically identified individual psychological characteristics that characterize to one degree or another the professional image of a teacher, made it possible to prepare his structural model, consisting of four components, including twelve relevant structural components. the first component is the ability to regulate one's behavior in communicative situations, the ability to adapt to the conditions of the social environment; the second component is the ability to independently overcome emerging life problems, a low level of conflict, communication and organizational skills, emotional intelligence; the third component is the ability to self-regulate emotional states that arise in a communicative situation, balanced emotionality, empathic abilities, developed reflexivity; the fourth component is communicative tolerance, the desire for selfdevelopment. I would like to note that the identification of the relevant structural components of the professional image of a modern teacher, as well as their classification and ranking according to the degree of significance, were based on the analysis of the obtained basic statistical data (average score, median, etc.), expert assessment. 


\section{LIST OF REFERENCES:}

[1] Afonin V.V. System Modeling: Study Guide/ - M.: BINOM. LZ, INTUIT, 2012.-- $231 \mathrm{p}$.

[2] Akhmedova A.A. Model and Simulation: Theoretical Aspect. // Access mode:https://files.scienceforum.ru/pdf/20 18/5571.pdf

[3] Brazhe R.A., Grishina A.A. Modeling in scientific knowledge. Ulyanovsk:U1STU, 2007.--58 p.

[4] Druzhinin V.N. Experimental Psychology - St. Petersburg: Piter Publishing House, 2000. - 320 p.

[5] Marasanov G.I. Methods for modeling and analyzing situations in social and psychological training. - Kirov, 2003. -$152 \mathrm{p}$.

[6] Narzikulova F.B. Socio-psychological model and conditions for the development of a teacher's professional image in postgraduate education. // BULLETIN OF INTEGRATIVE PSYCHOLOGY. International Academy of Psychological Sciences. Journal for psychologists. No. 20. - 2020. RUSSIA. - page: 89 -93.

[7] Narzikulova F.B. Theoretical and methodological foundations of the study of the development of the professional image of a teacher in psychological science. // Monograph. - Samarkand: ed. RTSPPKIPPKRNOSO, - 2019. -- p. 215.

[8] V.V. Nikandrov Modeling method in psychology. - SPb .: Rech, 2003 . - 64 p.

[9] A.F.Cherdantsev Model as a mental image. $/ /$ Access mode:https://uchebnikfree.com/gosudarst va-prava-teoriya/model-kak-myislennyiy3601 . 